\title{
Characteristics of patients seeking a health promotion and weight reduction program in primary care
}

This article was published in the following Dove Medical Press journal: Journal of Multidisciplinary Healthcare

\author{
Marie Bräutigam Ewe' \\ Marie Lydell ${ }^{2}$ \\ Håkan Bergh ${ }^{1,3}$ \\ Cathrine Hildingh ${ }^{2}$ \\ Amir Baigi ${ }^{1,3}$ \\ Jörgen Månsson' \\ 'Department of Public Health and \\ Community Medicine/Primary \\ Health Care, Sahlgrenska Academy \\ at the University of Gothenburg, \\ Gothenburg, Sweden; ${ }^{2} \mathrm{CVHI}-\mathrm{Centre}$ \\ of Research on Welfare, Health and \\ Sport, School of Health and Welfare, \\ Halmstad University, Halmstad, \\ Sweden; ${ }^{3}$ Research and Development \\ Unit Halland, Region of Halland, \\ Halmstad, Sweden
}

Purpose: An important task in primary health care (PHC) is to address lifestyle-related diseases. Overweight (OW) individuals make up a large proportion of PHC patients, and they increasingly have lifestyle-related illnesses that influence their quality of life. Structured health promotion and weight reduction programs could help these patients. The objective of this study was to explore the characteristics, lifestyle habits, and health conditions of individuals seeking a health promotion and weight reduction program in PHC.

Patients and methods: The study involved a comparative cross-sectional design performed in PHC in southwestern Sweden. The study population comprised 286 participants (231 women, aged 40-65 years, body mass index [BMI] $28-35 \mathrm{~kg} / \mathrm{m}^{2}$ ) who were recruited between March 2011 and April 2014 to the 2-year program by adverts in local newspapers and recruitment from three PHC centers. Two reference populations were used: a general population group and an OW group. The study population data were collected using a questionnaire, with validated questions regarding health, lifestyle, illnesses, and health care utilization.

Results: People seeking a health promotion and weight reduction program were mostly women. They had a higher education level and experienced worse general health than the OW population, and they visited PHC more frequently than both reference groups. They also felt more stressed, humiliated, had more body pain, and smoked less compared to the general population. However, they did not exercise less or had a lower intake of fruits and vegetables than either reference population.

Conclusion: Individuals seeking a weight reduction program were mostly women with a higher education level and a worse general health than the OW population. They used more health care services compared to the reference groups.

Keywords: lifestyle, overweight, primary health care, weight loss

\section{Introduction}

Being overweight (OW; body mass index $[\mathrm{BMI}]>25 \mathrm{~kg} / \mathrm{m}^{2}$ ) has reached epidemic proportions worldwide, with $>1.9$ billion $\mathrm{OW}$ individuals. The prevalence of obesity $\left(\mathrm{BMI}>30 \mathrm{~kg} / \mathrm{m}^{2}\right)$ more than doubled between 1980 and 2014, and >600 million individuals were obese in $2014 .{ }^{1}$ According to an annual report in Sweden, $43 \%$ of women and $57 \%$ of men were $\mathrm{OW}^{2}$

OW is associated with negative health implications, including cardiovascular disease, type 2 diabetes, various forms of cancer, ${ }^{3}$ psychiatric disorders (eg, depression and anxiety), and many symptoms, such as body pain, ${ }^{4,5}$ fatigue, and sleeping problems. ${ }^{6}$ Increasing OW (in terms of increasing BMI) is also associated with worse
Correspondence: Marie Bräutigam Ewe Capio Husläkarna Kungsbacka, Nygatan 10, 43430 Kungsbacka, Sweden $\mathrm{Tel}+46733132999$

Email marie.brautigam-ewe@

regionhalland.se 
health-related quality of life among women. ${ }^{7}$ Many OW individuals in a primary health care (PHC) program for weight reduction also felt more stressed than the general population. ${ }^{8}$ As a high BMI is associated with many health problems, OW individuals attend general practices more frequently; therefore, it is particularly important to prevent individuals from becoming OW or help them to lose weight by supporting them in adopting a healthy lifestyle. ${ }^{9}$ Healthrelated behavior, such as food intake, is also affected by socioeconomic position. Socioeconomically disadvantaged groups have a higher fat intake, a diet lower in fiber, and a lower consumption of fruits and vegetables. ${ }^{10}$

Personal difficulties occur more frequently among OW individuals, and many report that they are victims of stigmatization, marginalization, and discrimination. ${ }^{11}$ While external influences on weight, such as environmental factors, are important, it seems that internal factors, such as emotions, are of higher importance. ${ }^{12}$ However, further research on public attitudes toward and perception of OW is urgently needed to determine the prevailing degree of stigmatization. ${ }^{12}$ Additionally, weight loss programs have to consider both internal and external factors. Reported weight loss intervention attrition rates vary with individual expectations regarding weight loss. ${ }^{13}$ Unrealistic weight goals should be dealt with at the beginning of treatment. Individuals who terminate these programs early usually do not receive the support that they need to develop the strategies required for weight loss. ${ }^{14}$

It is therefore important to determine the characteristics of the population seeking a health promotion and weight reduction program in $\mathrm{PHC}$ and to determine how these characteristics differ from those of general and OW populations in order to improve the targeting of $\mathrm{PHC}$ resources to individualize treatment and reduce dropout rates. The objective of this study was to explore the characteristics, lifestyle habits, and health conditions of individuals seeking a health promotion and weight reduction program in $\mathrm{PHC}$.

\section{Materials and methods}

\section{Design and settings}

The study used a comparative cross-sectional design and was performed in a PHC setting in the southwestern part of Sweden. The study was performed at three PHC centers located in different cities and socioeconomic areas.

\section{Study population}

The participants were recruited (using adverts in local newspapers and direct recruitment at the three PHC centers) to a 2-year PHC weight reduction intervention study. The participants were randomized to a high- and low-intensive group. Both groups underwent laboratory tests and physical examinations, and filled in a questionnaire. They also received a cook book on the Nordic $\operatorname{diet}^{15}$ and a dietary lecture. The high-intensive group also underwent motivational interviewing. ${ }^{16}$ Both groups were followed up after 2 years. The inclusion criteria were being aged 40-65 years and having a BMI of $28-35 \mathrm{~kg} / \mathrm{m}^{2}$. The exclusion criteria were undergoing treatment that could be affected by study participation (such as chemotherapy or radiation), having known drug problems, and not understanding or being able to use Swedish in speech or writing.

\section{Reference populations}

Two reference populations were selected: one OW reference population (ORP) (40-65 years of age, BMI $28-35 \mathrm{~kg} / \mathrm{m}^{2)}$ from the same region as the study population and one general population (GRP; 40-65 years of age, mean BMI $26 \mathrm{~kg} / \mathrm{m}^{2}$ ). Data for both reference populations were obtained from the national population study known as "Health on Equal Terms" $(\mathrm{HLV})^{17}$ (Table 1).

\section{Data collection}

The study population's baseline data for the 2-year weight reduction program were collected between March 2011 and April 2014. Data were collected through Web-based questionnaires. The physical measurements (BMI, etc) were obtained and blood samples (hemoglobin A1c [HbAlc], etc) were taken by a nurse at the three PHCs during the first visit and after 2 years. The definition for each education level was based on the standards in Statistics Sweden, BA034. ${ }^{18}$ This classification consists of six education levels, with an algorithm defining three overall levels (low, medium, and high). The data collection for the two reference populations occurred between February and March 2014 using the HLV questionnaire. ${ }^{17}$

\section{Instruments}

\section{General Health Questionnaire (GHQ-I2)}

Psychological well-being was assessed using the GHQ-12, which was developed as a screening instrument for mental illness. ${ }^{19}$ The instrument, which has been validated and used worldwide, includes 12 questions and each uses an ordinal scale. The responses were dichotomized as good or impaired psychological well-being. ${ }^{20}$

\section{National health survey (HLV 20I4)}

The questions in the national health survey relate to physical and mental health, drug consumption, health care contacts, 
Table I Population characteristics

\begin{tabular}{|c|c|c|c|c|c|}
\hline Characteristics & Study population, $n=286$ & ORP, $n=747$ & GRP, $n=4,855$ & & \\
\hline & n (\%) & n (\%) & n (\%) & $P$-value I & $P$-value 2 \\
\hline Men & $55(19.1)$ & $418(56.0)$ & $2,181(45.0)$ & $<0.001$ & $<0.001$ \\
\hline Women & $231(80.8)$ & $329(44.0)$ & $2,674(55.0)$ & $<0.001$ & $<0.001$ \\
\hline Mean age, years (SD) & $55(7.1)$ & $53(7.7)$ & $53(7.5)$ & $<0.001$ & $<0.001$ \\
\hline BMI (SD) & $31(2.0)$ & $30(1.8)$ & $26(4.4)$ & $<0.001$ & $<0.001$ \\
\hline \multicolumn{6}{|l|}{ Education (men) } \\
\hline Low & $23(4 I .8)$ & $254(60.8)$ & $\mathrm{I}, 09 \mathrm{I}(50.4)$ & 0.007 & 0.230 \\
\hline Middle & $24(43.6)$ & $102(24.4)$ & $675(30.9)$ & 0.003 & 0.045 \\
\hline High & $8(14.5)$ & $60(14.4)$ & $408(18.7)$ & 0.984 & 0.429 \\
\hline \multicolumn{6}{|l|}{ Education (women) } \\
\hline Low & $95(4 I . I)$ & $165(50.3)$ & $\mathrm{I}, 188(44.5)$ & 0.034 & 0.333 \\
\hline Middle & $82(35.5)$ & $101(30.8)$ & $825(30.9)$ & 0.234 & 0.148 \\
\hline High & $54(23.4)$ & 62 (I8.9) & $655(24.6)$ & 0.186 & 0.708 \\
\hline
\end{tabular}

Notes: $P$-value I (chi-squared test) = study population compared to the overweight reference population $(\mathrm{ORP})\left(\mathrm{BMl}: 28-35 \mathrm{~kg} / \mathrm{m}^{2}\right) . P$-value 2 (chi-squared test) $=$ study population compared to the general reference population (GRP). Both reference populations were from a national health survey (HLV 20I4). Bold values indicate significance. Abbreviation: BMI, body mass index.

dental health, lifestyle, economic conditions, labor and employment, safety, security, and social relations. The questionnaire includes 80 issues. The survey has been administered nationally every year in Sweden since 2004, and at the regional level, it is performed every fourth year. In this study, we selected seven of the questionnaire domains: health status, health conditions, humiliation, symptoms, diseases, health care visits, and lifestyle.

The question "How would you rate your general health condition?" had a 5-point ordinal response scale (ranging from very good to very bad), which was converted into a dichotomous item consisting of the options good and bad. ${ }^{17}$ Dichotomization was also performed for the following domains (which contained items assessed using ordinal scales): health conditions, humiliation, pain symptoms, sickness, health care visits, and lifestyle. The other variables were items with dichotomous responses in their original forms (Figure 1).

\section{Statistics}

The study population was compared with the two reference populations. Descriptive statistics were used to obtain the primary results. For comparison between populations, the chi-squared test was performed. The significance level was set at $P=0.05$.

\section{Ethical approval}

The Central Ethical Review Board of the University of Stockholm granted permission for this study (no 29-2010). Additionally, prior ethics approval was obtained for the 2015 intervention health care study Dietary Advice on Prescription "DAP" (no 2010/543). Participants were informed about the aim of the study, their right to withdraw at any time without consequences, and that the data would be stored and analyzed confidentially and only be available to the researchers. When the participants agreed to participate, they were asked to sign a consent form.

\section{Results}

There were 286 participants (231 women) in the weight reduction study, with an overall response rate of $93 \%(n=266)$. There were more women in the study population compared to the two reference populations (Table 1). The mean age was 55 years (SD 7.1), and the mean BMI was 31 (SD 2.0). Both values were higher than those of the reference populations (Table 1). Most participants in the study population had a low or medium level of education, but there were more participants with a low education level in the OW reference population (Table 1). There were no significant differences in education level between the three PHC centers.

\section{Study population compared to the OW reference population (ORP)}

There was no difference in self-reported well-being in the study population compared to the ORP, but a lower proportion in the study population reported good general health (Tables 2 and 3). In contrast, oral health was better in the study population than in the ORP.

Regarding health care consumption for women, the level was significantly higher among the study participants 


\begin{tabular}{|c|c|c|}
\hline \multicolumn{3}{|c|}{ General health*, blood pressure*, diabetes* } \\
\hline $1+2$ & \multicolumn{2}{|c|}{ Good } \\
\hline $4+5$ & \multicolumn{2}{|l|}{ Bad } \\
\hline \multicolumn{3}{|c|}{ Stress, pain, anxiety, fatigue } \\
\hline$I=I$ & \multicolumn{2}{|l|}{ Good } \\
\hline $2+3+4=2$ & \multicolumn{2}{|l|}{ Bad } \\
\hline \multicolumn{3}{|l|}{ Sleep } \\
\hline $\mathrm{I}=\mathrm{I}$ & \multicolumn{2}{|l|}{ Good } \\
\hline $2+3=2$ & \multicolumn{2}{|l|}{ Bad } \\
\hline \multicolumn{3}{|c|}{ Physician, district nurse, psychologist, physiotherapist } \\
\hline$I=I$ & \multicolumn{2}{|c|}{ No } \\
\hline $2+3=2$ & \multicolumn{2}{|l|}{ Yes } \\
\hline \multicolumn{3}{|c|}{ Humiliation } \\
\hline$I=I$ & \multicolumn{2}{|l|}{ No } \\
\hline $2+3=2$ & \multicolumn{2}{|l|}{ Yes } \\
\hline \multicolumn{3}{|c|}{ Physical activity } \\
\hline \multicolumn{3}{|c|}{ Four independent subgroups: } \\
\hline \multicolumn{3}{|l|}{ Low $=1$} \\
\hline \multicolumn{3}{|l|}{ Other $=0$} \\
\hline \multicolumn{3}{|c|}{ Moderate $=1$} \\
\hline \multicolumn{3}{|l|}{ Other $=0$} \\
\hline \multicolumn{3}{|c|}{ Regular $=1$} \\
\hline \multicolumn{3}{|l|}{ Other $=0$} \\
\hline \multicolumn{3}{|l|}{ High=I } \\
\hline \multicolumn{3}{|l|}{ Other $=0$} \\
\hline \multicolumn{3}{|c|}{ Fruits and vegetables } \\
\hline \multicolumn{3}{|c|}{$1+2+3+4+5+6=1 \quad$ Eat } \\
\hline \multicolumn{2}{|l|}{$7=2$} & Not eat \\
\hline \multicolumn{3}{|c|}{ Dental health* } \\
\hline $1+2=1$ & \multicolumn{2}{|l|}{ Good } \\
\hline $4+5=2$ & \multicolumn{2}{|l|}{ Bad } \\
\hline Smoking & ffine-gr & und tobacco (snuff) \\
\hline$I=I$ & Yes & \\
\hline $2=2$ & No & \\
\hline
\end{tabular}

Figure I Dichotomization criteria used for the reference groups from a national health survey in Sweden (HLV 20I4).

Notes: *Had five alternatives (based on an ordinal scale). To obtain as pure dichotomous alternatives as possible, the neutral option (option 3) was removed and the answers were dichotomized by merging options $\mathrm{I}+2$ and correspondingly merging options $3+4$.

compared to the ORP for visits to district nurses, physiotherapists, and psychologists; however, they visited physicians less frequently. Regarding men, only the visits to physiotherapists were increased compared to the ORP.

The men in the study population (but not women) also reported more humiliation than the men in the ORP (Tables 2 and 3).
Regarding pain, the women in the study population had more hand pain than the ORP.

Regarding diabetes, neither women nor men showed an increased prevalence compared to the corresponding subgroups in the ORP (Tables 2 and 3).

In terms of lifestyle habits, tobacco use did not differ significantly between the study population and the ORP (Tables 2 and 3). There were no significant differences in physical activity for women; however, there were fewer men with low activity level in the study population than the ORP. There were no significant differences in the consumption of fruits and vegetables.

\section{Study population compared to the general reference population (GRP)}

The study population reported worse general health than the GRP; however, oral health was better in the study population.

Regarding health care consumption for women, there were significantly higher levels among the study participants than the GRP for visits to district nurses, physiotherapists, and psychologists; however, they visited physicians less frequently.

Both women and men in the study population reported more stress and humiliation than the corresponding subgroups in the GRP, and women reported more fatigue but less anxiety (Tables 2 and 3). Regarding pain, the women in the study population had more back pain than the women in the GRP, while the men had more shoulder pain than the men in the GRP.

Both women and men in the study population had higher blood pressure than the corresponding groups in the GRP, but there was no increased prevalence of diabetes compared to the prevalence in the GRP.

\section{Discussion}

The individuals seeking a weight reduction program were mostly women and they had a higher education level than the ORP. They also differed in terms of having worse general health than the ORP, despite not reporting worse psychological well-being, as measured by the GHQ12. ${ }^{19}$ General health includes physical health, and many of the study participants had body pain, which could have affected how they rated their health. A previous survey that followed OW and obese individuals between 2002 and 2010 showed that the risk of pain and low general health increased with increasing BMI. ${ }^{21}$ However, our findings differed from those of another study, which found both worse general health and impaired psychological well-being in obese women in Spain. ${ }^{22}$ 
Table 2 Health questionnaire responses among women

\begin{tabular}{|c|c|c|c|c|c|}
\hline \multirow[t]{2}{*}{ Health factors } & Study population, $n=212$ & ORP, $n=329$ & GRP, $n=2,674$ & $P$-value I & $P$-value 2 \\
\hline & $\%(n)$ & $\%(n)$ & $\%(n)$ & & \\
\hline \multicolumn{6}{|l|}{ Health status } \\
\hline Good general health & $50(101 / 202)$ & $65(2 / 2 / 326)$ & $70(I, 843 / 2,633)$ & $<0.001$ & $<0.001$ \\
\hline Good oral health & $91(147 / 161)$ & $75(242 / 323)$ & $76(2,024 / 2,663)$ & $<0.001$ & $<0.001$ \\
\hline Good well-being & $84(151 / 180)$ & $77(253 / 329)$ & $82(2,184 / 2,664)$ & 0.062 & 0.498 \\
\hline \multicolumn{6}{|l|}{ Health condition } \\
\hline Anxiety & $35(63 / 179)$ & $40(131 / 328)$ & $45(1,196 / 2,657)$ & 0.269 & 0.009 \\
\hline Sleep disorders & $45(81 / 179)$ & $4 I(134 / 328)$ & $4 \mathrm{I}(\mathrm{I}, 090 / 2,658)$ & 0.384 & 0.293 \\
\hline Stress & $62(111 / 179)$ & $54(178 / 329)$ & $54(1,436 / 2,660)$ & 0.082 & 0.038 \\
\hline \multicolumn{6}{|l|}{ Humiliation } \\
\hline Humiliation & $34(60 / 176)$ & $27(87 / 324)$ & $22(582 / 2,644)$ & 0.101 & $<0.00$ I \\
\hline \multicolumn{6}{|l|}{ Symptoms } \\
\hline Shoulder & $66(119 / 180)$ & $62(202 / 325)$ & $60(I, 59 I / 2,65 I)$ & 0.372 & 0.111 \\
\hline Hands & $64(115 / 180)$ & $55(181 / 329)$ & $50(1,329 / 2,658)$ & 0.049 & $<0.00 \mathrm{I}$ \\
\hline Back & $64(115 / 180)$ & $58(190 / 328)$ & $52(1,372 / 2,639)$ & 0.187 & $<0.001$ \\
\hline Fatigue & $65(116 / 179)$ & $58(190 / 328)$ & $53(1,407 / 2,654)$ & 0.124 & 0.002 \\
\hline \multicolumn{6}{|l|}{ Disease } \\
\hline Hypertension & $31(54 / 174)$ & $27(87 / 322)$ & $21(533 / 2,538)$ & 0.346 & 0.002 \\
\hline Diabetes & 4 (7/I77) & $6(19 / 322)$ & $4(80 / 1,992)$ & 0.340 & 0.999 \\
\hline \multicolumn{6}{|l|}{ Health care visits } \\
\hline Doctor & $22(29 /|3|)$ & $44(140 / 318)$ & $38(986 / 2,595)$ & $<0.001$ & $<0.001$ \\
\hline Nurse & $39(5 \mathrm{I} / \mathrm{I} 30)$ & $17(5 \mid / 302)$ & $22(549 / 2,495)$ & $<0.001$ & $<0.00$ I \\
\hline Psychologist & II (I4/I3I) & $4(12 / 303)$ & $4(99 / 2,474)$ & 0.005 & $<0.00$ I \\
\hline Physiotherapist & $37(48 /|3|)$ & $17(52 / 308)$ & $12(299 / 2,493)$ & $<0.00$ I & $<0.00$ I \\
\hline \multicolumn{6}{|l|}{ Lifestyle } \\
\hline Daily smoking & $5(9 / 178)$ & $9(30 / 329)$ & $15(398 / 2,650)$ & 0.105 & $<0.00$ I \\
\hline Fine-ground tobacco (snuff) & $\mathrm{I}(2 / 177)$ & $3(10 / 325)$ & $4(I 13 / 2,626)$ & 0.153 & 0.044 \\
\hline Fruits/vegetables & $98(174 / 178)$ & $99(325 / 328)$ & $99(2,63 \mathrm{I} / 2,658)$ & 0.353 & 0.208 \\
\hline Low physical activity & $15(26 / 176)$ & $15(48 / 322)$ & II $(290 / 2,635)$ & 0.999 & 0.104 \\
\hline Moderate physical activity & $43(76 / 176)$ & $48(155 / 322)$ & $46(I, 2 \mid 2 / 2,635)$ & 0.285 & 0.439 \\
\hline Regular physical activity & $25(44 / 176)$ & $23(74 / 322)$ & $24(632 / 2,635)$ & 0.616 & \begin{tabular}{|l|}
0.764 \\
\end{tabular} \\
\hline High physical activity & $17(30 / 176)$ & $14(45 / 322)$ & $19(501 / 2,635)$ & $0.37 I$ & 0.512 \\
\hline
\end{tabular}

Notes: $P$-value I (chi-squared test) $=$ study population compared to the overweight reference population (ORP) (BMI: $\left.28-35 \mathrm{~kg} / \mathrm{m}^{2}\right)$. $P$-value 2 (chi-squared test) $=$ study population compared to the general reference population (GRP). Both reference populations were from a national health survey (HLV 20I4). Bold values indicate significance.

Oral health was better in the study population compared to both the ORP and GRP. There is a link between increased education and better oral health and also between increased education and less smoking, which also leads to better oral health. $^{23,24}$

The study population, particularly women, utilized more health care services than the reference groups, except for general practitioner visits, and other studies also demonstrated that women tend to use health care more frequently than men and medical conditions (eg, hypertension, diabetes, and mental illness) were common. ${ }^{25,26} \mathrm{OW}$ individuals are often prepared to try many different solutions to improve their general health, ${ }^{27}$ which may be one of the reasons why they were frequent visitors to PHC facilities.

The study population felt more humiliated than the general population, in accordance with other studies..$^{28,29}$
A previous study showed that, compared with diseases "believed to be caused by individuals themselves", such as obesity and HIV/AIDS, persons with diseases experienced less sympathy both in health care settings and in wider society. ${ }^{30}$ This is not a fact or the opinion of a health professional but the opinion or perception of some parts of the population. There are documented links between perceived weight stigmatization and adverse health consequences, such as binge eating, increased food consumption, avoidance of physical activity, physiological stress, and impaired weight loss outcomes. ${ }^{31}$

Another finding that distinguished our study participants from the GRP was that they had more symptoms, such as shoulder, back, and hand pain, stress, and fatigue, than the GRP. It has been shown that there is a relationship between BMI, chronic pain, and reduced quality of life, and it seemed 
Table 3 Health questionnaire responses among men

\begin{tabular}{|c|c|c|c|c|c|}
\hline \multirow[t]{2}{*}{ Health factors } & Study population, $n=54$ & ORP, $n=4 \mid 8$ & GRP, $n=2,181$ & $P$-value I & $P$-value 2 \\
\hline & $\%(n)$ & $\%(n)$ & $\%(n)$ & & \\
\hline \multicolumn{6}{|l|}{ Health } \\
\hline Good general health & $43(22 / 5 I)$ & $69(286 / 4 \mid 4)$ & $70(1,504 / 2,149)$ & $<0.001$ & $<0.001$ \\
\hline Oral health & $95(35 / 37)$ & $70(288 / 4 \mathrm{II})$ & $7 \mid(I, 54 I / 2,|7|)$ & 0.001 & 0.001 \\
\hline Well-being & $91(4 I / 45)$ & $89(37 \mid / 4 I 7)$ & $87(I, 843 / 2, I 18)$ & 0.682 & 0.429 \\
\hline \multicolumn{6}{|l|}{ Health condition } \\
\hline Anxiety & $30(13 / 44)$ & $26(108 / 4 \mid 7)$ & $26(532 / 2,161)$ & 0.567 & 0.550 \\
\hline Sleep disorders & $36(16 / 45)$ & $35(146 / 416)$ & $3 \mid(67 \mid / 2,165)$ & 0.894 & 0.473 \\
\hline Stress & $62(28 / 45)$ & $50(208 / 4 \mid 7)$ & $4 I(887 / 2,164)$ & 0.126 & 0.005 \\
\hline \multicolumn{6}{|l|}{ Humiliation } \\
\hline Humiliation & $22(10 / 45)$ & $15(61 / 408)$ & $15(523 / 2,155)$ & $<0.001$ & $<0.001$ \\
\hline \multicolumn{6}{|l|}{ Symptoms } \\
\hline Shoulder & $66(29 / 44)$ & $52(2|6 / 4| 5)$ & $45(972 / 2,160)$ & 0.077 & 0.006 \\
\hline Hands & $5 I(23 / 45)$ & $48(20|/ 4| 8)$ & $43(930 / 2,163)$ & 0.702 & 0.284 \\
\hline Back & $60(27 / 45)$ & $50(208 / 4 \mid 5)$ & $46(992 / 2,156)$ & 0.203 & 0.062 \\
\hline Fatigue & $49(22 / 45)$ & $43(179 / 4 \mid 7)$ & $42(908 / 2,162)$ & $0.44 I$ & 0.347 \\
\hline \multicolumn{6}{|l|}{ Diseases } \\
\hline Hypertension & $52(22 / 42)$ & $44(|82 / 4| 3)$ & $24(498 / 2,073)$ & 0.321 & $<0.001$ \\
\hline Diabetes & $5(2 / 44)$ & $6(19 / 322)$ & $7(139 / 1,992)$ & 0.792 & 0.606 \\
\hline \multicolumn{6}{|l|}{ Health care visits } \\
\hline Doctor & $28(9 / 32)$ & $36(146 / 406)$ & $32(667 / 2,085)$ & 0.363 & 0.630 \\
\hline Nurse & $28(9 / 32)$ & $27(107 / 396)$ & $22(442 / 2,008)$ & 0.903 & 0.412 \\
\hline Psychologist & $3(1 / 32)$ & $2(8 / 392)$ & $3(60 / 1,990)$ & 0.703 & 0.999 \\
\hline Physiotherapist & $34(I I / 32)$ & $9(35 / 394)$ & $8(161 / 2,009)$ & $<0.001$ & $<0.001$ \\
\hline \multicolumn{6}{|l|}{ Lifestyle } \\
\hline Daily smoking & $2(1 / 45)$ & $9(37 / 4 \mid 5)$ & $13(279 / 2,144)$ & 0.107 & 0.029 \\
\hline Fine-ground tobacco (snuff) & $18(8 / 45)$ & $27(113 / 4 \mid 8)$ & $20(429 / 2,147)$ & 0.192 & 0.740 \\
\hline Fruits/vegetables & $93(42 / 45)$ & $95(394 / 415)$ & $97(2,095 / 2,160)$ & 0.566 & 0.124 \\
\hline Low physical activity & $7(3 / 44)$ & $19(78 / 409)$ & $13(279 / 2,145)$ & 0.048 & 0.240 \\
\hline Moderate physical activity & $45(20 / 44)$ & $48(196 / 409)$ & $46(987 / 2,145)$ & 0.705 & 0.895 \\
\hline Regular physical activity & $30(13 / 44)$ & $22(90 / 409)$ & $25(536 / 2,145)$ & 0.230 & 0.449 \\
\hline High physical activity & $18(8 / 44)$ & II (45/409) & $16(343 / 2,145)$ & 0.170 & 0.721 \\
\hline
\end{tabular}

Notes: $P$-value I (chi-squared test) = study population compared to the overweight reference population (ORP) (BMI: $\left.28-35 \mathrm{~kg} / \mathrm{m}^{2}\right) . P$-value $2($ chi-squared test) $=$ study population compared to the general reference population (GRP). Both reference populations were from a national health survey (HLV 20I4). Bold values indicate significance.

to be aligned with increasing BMI. ${ }^{22}$ As mentioned, the study population also reported more stress than the GRP. Perceived stress is connected with a higher consumption of fat, snacks, and fast food but not necessarily a lower intake of fruits and vegetables, ${ }^{32}$ as was the case in our study. The women in the study also felt more fatigue compared to the women in the GRP, despite the fact that there was no difference in sleeping disorders. There could be a stronger connection between stress, anxiety, and fatigue among women because they often take on more responsibilities in the home. ${ }^{33}$ Diabetes has been shown to be common among OW individuals,${ }^{34}$ but in our study, the study participants did not show a higher prevalence than the other reference groups. The study participants' blood pressure levels were higher compared to the GRP, which may be explained by higher BMI and increased stress. ${ }^{35,36}$

Negative lifestyle habits have been found to be independent determinants of frequent attendance at general practitioners' offices; however, higher education and employment had a reduced attendance levels. ${ }^{25,26}$ The male study participants had a lower prevalence of low physical activity than the men in the ORP, which may be explained by their higher education levels, although a previous study suggests that self-reported physical activity questionnaires are less valid in populations with lower education levels. ${ }^{37}$ Daily smoking has decreased in Sweden; however, smoking is still linked to low education levels, ${ }^{38}$ which could explain the lower smoking prevalence in the study population compared to the ORP. 


\section{Methodological discussion}

The GHQ-12 appears to be a good proxy for assessments of depressive disorder when used in public health surveys. ${ }^{39}$ Self-rated health is a widely used measure of population health status. It correlates with physical health, functional capacity, and psychological well-being, and it is a significant predictor of morbidity, mortality, and health care utilization. ${ }^{40}$

The strengths of this study include the possibility for comparisons, both at the national and regional levels. The use of validated instruments increases the validity of the questions. The study assessments did not occur at exactly the same time as the data collection for the two reference groups; however, they were matched to approximately the same time period (February and March 2014). Furthermore, the amalgamation of responses into dichotomized responses can reduce the nuance in the responses, and we used the same method as that used in the reference population research. ${ }^{17}$

The study population consisted of more women than men ( $81 \%$ women), which is often the case in these types of intervention studies about weight loss ${ }^{41}$ The study population was self-selected, which may explain the higher education level and higher proportion of women compared to those in the ORP and GRP, which could have influenced the results. Women in their 50s, with low education and chronic illness, sought more PHC treatment, ${ }^{42}$ though our study showed that women with high education sought more PHC treatment. However, these are the conditions in a PHC setting. The study participants were divided by gender to determine whether there were any major differences with corresponding subgroups in the ORP and GRP (Tables 2 and 3), and it was found that there were differences in the frequency of health care attendance and symptoms such as anxiety and fatigue. Our study participants had a mean age of 2 years older than the ORP and GRP participants, which is unlikely to have affected the outcomes. Three PHC centers were chosen to ensure socioeconomic diversity; however, the education level was higher in the study population than the ORP (but not the GRP). People with high school diplomas, regardless of their literacy levels and other sociodemographic factors, are more likely to seek and use health information. Education levels and literacy levels are both strongly linked to health outcomes. ${ }^{43}$

\section{Conclusion}

The individuals seeking the weight reduction program were mostly women, they had a higher education level than the OW population, and they also had worse general health, despite not reporting worse psychological well-being. They also utilized more health care services, except for general practitioner visits.

The men in the study population differed from the women, with more self-reported humiliation compared to the OW population among men but not among women. The study participants did not have more stress, diseases, or body pain compared to the OW population; however, they differed from the general population in terms of more humiliation and more stress but better lifestyle habits regarding smoking. OW is a complex condition, and these findings could be important to create improved professional PHC teams and adapt health care resources to each individual.

\section{Acknowledgments}

We would like to thank Prof Gunnar Johansson, who initiated the weight reduction program. We thank Capio Sjukvård AB for the support and Sparbanksstiftelsen Varberg for the production of this publication which does not constitute an endorsement of the study contents, which reflect the views only of the authors, therefore Capio Sjukvård $\mathrm{AB}$ and Sparbanksstiftelsen Varberg cannot be held responsible for any use of the information contained therein.

\section{Disclosure}

The authors report no conflicts of interest in this work.

\section{References}

1. World Health Organization [homepage on the Internet]. Geneva: Obesity and overweight; 2014. Available from: www.who.int/mediacentre/ factsheets/fs311/en/. Accessed Jan 22, 2017.

2. Public Health Agency of Sweden 2016. [homepage on the Internet] Sweden. Available from: www.folkhalsomyndigheten.se/ 2017. Accessed March, 2017.

3. National Task Force on the prevention and treatment of obesity. Overweight, obesity and health risk. Arch Intern Med. 2000;160(7):898-904.

4. Coaccioli S, Masia F, Celi G, Grandone I, Crapa ME, Fatati G. Dolore Cronico nell'obecità: studio ossevazionale quali-quantitativo [Chronic pain in the obese: a quali-quantitative observational study]. Recenti Prog Med. 2014;105(4):151-154. Italian.

5. Paans NP, Bot M, Gibson-Smith D, et al. The association between personality traits, cognitive reactivity and body mass index is dependent on depressive and/or anxiety status. J Psychosom Res. 2016;89: 26-31.

6. Fukuda K, Straus SE, Hickie I, Sharpe MC, Dobbins JG, Komaroff A. The chronic fatigue syndrome. Ann Intern Med. 1994;121(12): 953-959.

7. Korhonen PE, Seppälä T, Järvenpää S, Kautiainen H. Body mass index and health-related quality of life in apparently healthy individuals. Qual Life Res. 2014;23(1):67-74.

8. Metz U, Welke J, Esch T, Renneberg B, Braun V, Heintze C. Perception of stress and quality of life in overweight and obese people-implications for preventive consultancies in primary care. Med Sci Monit 2009;15(1):PH1-PH6

9. van Steenkiste B, Knevel MF, van den Akker M, Metsemakers JFM. Increased attendance rate: BMI matters, lifestyles don't. Results from the Dutch SMILE study. Fam Pract. 2010;27(6):632-637. 
10. Giskes K, Avendaňo M, Brug J, Kunst AE. A systematic review of studies on socioeconomic inequalities in dietary intakes associated with weight gain and overweight/obesity conducted among European adults. Obes Rev. 2010;11(6):413-429.

11. Deck KM, Haney B, Fitzpatrick CF, Phillips SJ, Tiso SM. Prescription for obesity: eat less and move more. Is it really that simple? Open $J$ Nurs. 2014;4(9):656-662.

12. Sikorski C, Luppa M, Kaiser M, et al. The stigma of obesity in the general public and its implications for public health - a systematic review. BMC Public Health. 2011;11(1):661.

13. Dalle Grave R, Calugi S, Molinari E, et al; QUOVADIS Study Group. Weight loss expectations in obese patients and treatment attrition: an observational multicenter study. Obes Res. 2005;13(11):1961-1969.

14. De Panfilis C, Torre M, Cero S, et al. Personality and attrition from behavioral weight-loss treatment for obesity. Gen Hosp Psychiatry. 2008;30(6):515-520.

15. Adamsson V, Reumark A, Fredriksson IB, et al. Effects of a healthy Nordic diet on cardiovascular risk factors in hypercholesterolaemic subjects: a randomized controlled trial (NORDIET). J Intern Med. 2011;269(2): $150-159$.

16. Graneheim UH, Lundman B. Qualitative content analysis in nursing research: concepts, procedures and measures to achieve trustworthiness. Nurse Educ Today. 2004;24(2):105-112.

17. National Health Survey 2014. [homepage on the Internet]: Sweden. Available from: www.fhi.se. Accessed January, 2017.

18. Utbildningsnivån SUN 2000 NIVA. The Education codes and levels (SUN 2000). Statistiska Centralbyrån (SCB), Statistics Sweden 2018; Örebro, Sweden. Available from: https:/www.scb.se/sv_/Hitta-statistik/ Publiceringskalender/Visa-detaljerad-information/?publobjid=2061. Accessed April, 2018.

19. Goldberg DP, Williams PA. User's guide to the general health questionnaire. Windsor: NFER/Nelson. Soc Psych Psychiatric Epidem. 1988;11:213-218.

20. Lundin A, Åhs J, Åsbring N, et al. Discriminant validity of the 12-Item version of the general health questionnaire in a Swedish case-control study. Nord J Psychiatry. 2017;71(3):171-179.

21. Holmgren M, Lindgren A, de Munter J, Rasmussen F, Ahlström G. Impacts of mobility disability and high and increasing body mass index on health-related quality of life and participation in society: a populationbased cohort study from Sweden. BMC Public Health. 2014;14(1): 381 .

22. Martín-López R, Pérez-Farinós N, Hernández-Barrera V, de Andres AL, Carrasco-Garrido P, Jiménez-García R. The association between excess weight and self-rated health and psychological distress in women in Spain. Public Health Nutr. 2011;14(7):1259-1265.

23. Paulander J, Axelsson P, Lindhe J. Association between level of education and oral health status in 35-, 50-, 65- and 75-year-olds. J Clin Periodontol. 2003;30(8):697-704.

24. Axelsson P, Paulander J, Lindhe J. Relationship between smoking and dental status in 35-, 50-, 65-, and 75-year-old individuals. J Clin Periodontol. 1998;25(4):297-305.

25. Chen R, Tunstall-Pedoe H. Socioeconomic deprivation and waist circumference in men and women: The Scottish MONICA surveys 1989-1995. Eur J Epidemiol. 2005;20(2):141-147.
26. Koskela TH, Ryynanen OP, Soini EJ. Risk factors for persistent frequent use of the primary health care services among frequent attenders: a Bayesian approach. Scand J Prim Health Care. 2010;28(1):55-61.

27. Elfhag K, Rössner S. Who succeeds in maintaining weight loss? A conceptual review of factors associated with weight loss maintenance and weight regain. Obes Rev. 2005;6(1):67-85.

28. Kushner RF. The burden of obesity: personal stories, professional insights. Narrat Inq Bioeth. 2014;4(2):129-133.

29. Thomas SL, Hyde J, Karunaratne A, Herbert D, Komesaroff PA. Being 'fat' in today's world: a qualitative study of the lived experiences of people with obesity in Australia. Health Expect. 2008;11(4):321-330.

30. Puhl RM, Heuer CA. Obesity stigma: important considerations for public health. Am J Public Health. 2010;100(6):1019-1028.

31. Puhl R, Suh Y. Health consequences of weight stigma: implications for obesity prevention and treatment. Curr Obes Rep. 2015;4(2):182-190.

32. Barrington WE, Beresford SA, McGregor BA, White E. Perceived stress and eating behaviors by sex, obesity status, and stress vulnerability: findings from the vitamins and lifestyle (VITAL) study. J Acad Nutr Diet. 2014;114(11):1791-1799.

33. Jarosz PA, Davis JE, Yarandi HN, et al. Obesity in urban women: associations with sleep and sleepiness, fatigue and activity. Womens Health Issues. 2014;24(4):e447-e454.

34. American Diabetes Association. Standards of medical care in diabetes-2013. Diabetes Care. 2013;36(Suppl 1):S11-S66.

35. Higgins M, Kannel W, Garrison R, Pinsky J. Stokes J 3rd. Hazards of obesity-the Framingham experience. Acta Med Scand Suppl. 1988;723: 23-36.

36. Carroll D, Ring C, Hunt K, Ford G, Macintyre S. Blood pressure reactions to stress and the prediction of future blood pressure: effects of sex, age, and socioeconomic position. Psychosom Med. 2003;65(6):1058-1064.

37. Winckers ANE, Mackenbach JD, Compernolle S, et al. Educational differences in the validity of self-reported physical activity. BMC Public Health. 2015;15(1):1299.

38. Public Health Agency of Sweden 2017. [homepage on the Internet]. Sweden. Available from: https://www.folkhalsomyndigheten.se/livsvillkor-levnadsvanor/alkohol-narkotika-dopning-tobak-och-spel-andts/ tobak/utvecklingen-av-bruket/bruk-av-cigaretter-snus-och-e-cigaretteri-den-vuxna-befolkningen/. Accessed March, 2017.

39. Lundin A, Hallgren M, Theobald H, Hellgren C, Torgén M. Validity of the 12-Item version of the general health questionnaire in detecting depression in the general population. Public Health. 2016;136:66-74.

40. Candemir I, Ergun P, Kaymaz D. Efficacy of a multidisciplinary pulmonary rehabilitation outpatient program on exacerbations in overweight and obese patients with asthma. Wien Klin Wochenschr. 2017;129(19-20):655-664.

41. Melchart D, Löw P, Wühr E, Kehl V, Weidenhammer W. Effects of a tailored lifestyle self-management intervention (TALENT) study on weight reduction: a randomized controlled trial. Diabetes Metab Syndr Obes. 2017;10(10):235-245.

42. Gomes J, Machado A, Cavadas LF, et al. [The primary care frequent attender profile]. Acta Med Port. 2013;26(1):17-23. Portuguese.

43. Egerter S, Braveman P, Sadegh-Nobari T, Grossman-Kahn R, Dekker M. Issue Brief 6: Education and Health. Princeton, NJ: Robert Wood Johnson Foundation; 2009.
Journal of Multidisciplinary Healthcare

\section{Publish your work in this journal}

The Journal of Multidisciplinary Healthcare is an international, peerreviewed open-access journal that aims to represent and publish research in healthcare areas delivered by practitioners of different disciplines. This includes studies and reviews conducted by multidisciplinary teams as well as research which evaluates the results or conduct of such teams or health

\section{Dovepress}

care processes in general. The journal covers a very wide range of areas and welcomes submissions from practitioners at all levels, from all over the world. The manuscript management system is completely online and includes a very quick and fair peer-review system. Visit http://www.dovepress.com/ testimonials.php to read real quotes from published authors. 